\title{
Finite Element Analysis on the Stress Intensity Factor in SENT Specimen of Clam Steel
}

\author{
Bowei Liu ${ }^{1, a}$, Jun Cai ${ }^{1, b}$ and YD Wang ${ }^{2, c}$ \\ ${ }^{1}$ Beijing Key Laboratory of Passive Safety Technology for Nuclear Energy School of Nuclear \\ Science and Engineering, North China Electric Power University, Beijing, 102206, China \\ ${ }^{2}$ State Key Laboratory of Metal Materials, Beijing University Science and Technology, Beijing, \\ 100083, China \\ aemail: 87119542@qq.com, bemail: caijun@ncepu.edu.cn
}

Keywords: Clam steel; Single-edged notched tension; Finite element analysis; Ansys; Stress intensity factor.

\begin{abstract}
The Ansys finite element software is used to calculate the crack opening displacement and Stress intensity factor (SIF) for Single-edged notched tension (SENT) specimen of Clam steel under the tension of $1000 \mathrm{~N}$. During the simulation, the crack opening positions for five groups and the different crack length were set up. The numerical simulation shows that the Model I intensity factor $\left(\mathrm{K}_{\mathrm{I}}\right)$ is larger one order than the Model II intensity factor $\left(\mathrm{K}_{\mathrm{II}}\right)$, the values of the SIF is not related to the crack opening displacement. The SIF is more influenced by the crack opening position and the crack size.
\end{abstract}

\section{Introduction}

The finite element method has been widely used to study the SIF of the crack tip. Lakkundi [1] used finite element to predict of crack growth in aircraft engine bleed air T-JOINT ducts, found that in a T-joint duct subjected to internal pressure and axial loading, the SIF at the deepest points increases as the crack depth-to-thickness ratio increases. Li [2] used finite element method to do the Numerical analysis of SIF and security service evaluation on thin-walled pipeline's semi-elliptical crack in American Standard Straight Pipe Thread under heat-stress coupling load, concluded that the influence of the thermal composition's relative difference on $K_{I}$ value is greater than that of other compositions in coupling load. Ismail [3] did the finite element analysis on the stress intensity factor under combined bending and torsion loading, concluded that SIF increased as the crack depth-to-thickness ratio increases under bending loading, for the torsion moment, the SIF is decreased when the depth-to-thickness is increased and these phenomena occurred at the middle position of the circular cross section of the bar. Sultan [4] used finite element to simulate the crack mouth opening displacement (CMOD) of single-edged notched tension (SENT) Specimen and compared with the experimental data, numerical results show that CMODs are in good agreement with experimental data for cases of small crack lengths and lower values of applied load. In this paper, we study on the mechanical properties of ferritic/martensitic steel. The ferritic/martensitic steel (Clam steel) is considered as candidate structural material for future fusion reactors [5]. We calculate the SIF of rectangular clam steel plate with a SENT crack model. The stress intensity factors of different crack locations and different crack lengths are discussed.

\section{Theory and calculation method}

The stress intensity factor and crack mouth opening displacement are obtained by using Ansys software. Detailed finite element analyses are performed on a 2D plane stress model 1-T SENT specimen, having a thickness of $2 \mathrm{~mm}$. The analysis is carried out on the rectangular specimen with length $L=60 \mathrm{~mm}$ and width $D=30 \mathrm{~mm}$ The finite element model and boundary condition are shown in Figure 1. Where, $x$ indicates the distance from the fixed edge to the crack. The crack location is determined by $x / L$, divided into five groups, we consider $x / L$ as $1 / 8,1 / 4,1 / 2,3 / 4,7 / 8$ respectively. The crack length is expressed by symbol $a$, simulation is carried out for $1 / 15 \leq a / D \leq 1 / 5$ which 
corresponds to the crack length of $2 \mathrm{~mm}$ to $6 \mathrm{~mm}$ in a total width of $30 \mathrm{~mm}$.

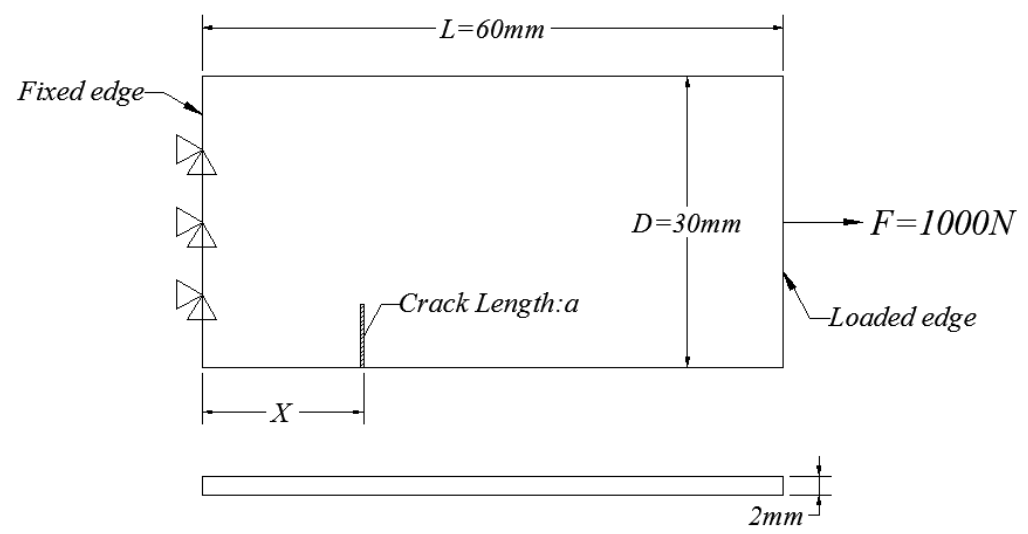

Fig.1 Single edge cracked finite element model of Clam steel and boundary condition

Chemical composition (wt.\%) of the clam steel is given in Table.1 . The linear elastic material properties are given as follows, Elastic modulus E $=218 \mathrm{GPa}$, Poisson ratio $\gamma=0.33$, yield strength $\sigma=514 \mathrm{MPa}$ and density $\rho=7.78 \mathrm{~g} / \mathrm{cm}^{3}$.

Table1 Chemical composition of CLAM stainless steel (wt./\%)

\begin{tabular}{cccccccccr}
\hline & $\mathrm{Fe}$ & $\mathrm{Cr}$ & $\mathrm{Mn}$ & $\mathrm{W}$ & $\mathrm{Si}$ & $\mathrm{V}$ & $\mathrm{C}$ & $\mathrm{Ta}$ & $\mathrm{Ni}$ \\
\hline Bal. & 8.82 & 0.37 & 1.10 & 0.005 & 0.19 & 0.10 & 0.068 & 0.021 & \\
\hline
\end{tabular}

In the calculations of the SENT crack model, a mesh refinement is required at the crack tip region due to that the variation of stress and strain fields around the crack tip are very large. Finite element models of the plate with $a=2 \mathrm{~mm}, x / L=1 / 8$ is shown in Figure 2 . For the other cracks, the meshes are refined similarly.

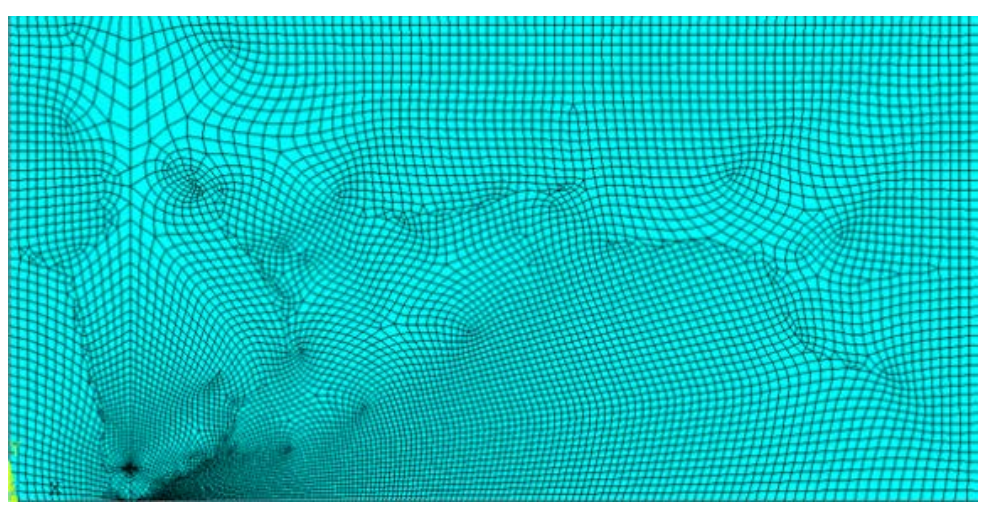

Fig.2 meshes for clam steel plate with $a=2 \mathrm{~mm}, x / L=1 / 8$

The intensity factors are divided into three categories according to the basic type of crack.

Model I intensity factor $\left(\mathrm{K}_{\mathrm{I}}\right)$, caused by normal stress perpendicular to the crack plane.

Model II intensity factor $\left(\mathrm{K}_{\mathrm{II}}\right)$, caused by shear stress on the leading edge of a vertical crack.

Model III intensity factor $\left(\mathrm{K}_{\mathrm{III}}\right)$, caused by the dislocation of the crack surface is parallel to the leading edge of the crack in its own plane.

The effective SIF can be represented as in Eq. (1) .In the way of present loading, the $\mathrm{K}_{\mathrm{III}}$ can be considered to be zero.

$$
\mathrm{K}_{\mathrm{eff}}=\sqrt{\mathrm{K}_{\mathrm{I}}^{2}+\mathrm{K}_{\mathrm{II}}^{2}+\frac{\mathrm{K}_{\mathrm{II}}^{2}}{1-v}}
$$

\section{Results and Discussions}

The numerical values of $K_{I}$ and $K_{\text {II }}$ for different crack locations and crack length are shown in Figure 3. 


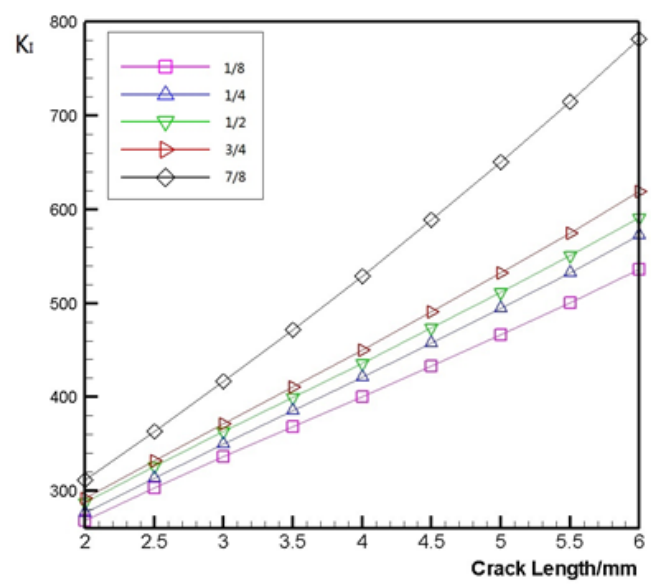

(a) $\mathrm{K}_{\mathrm{I}}$ Vs crack length

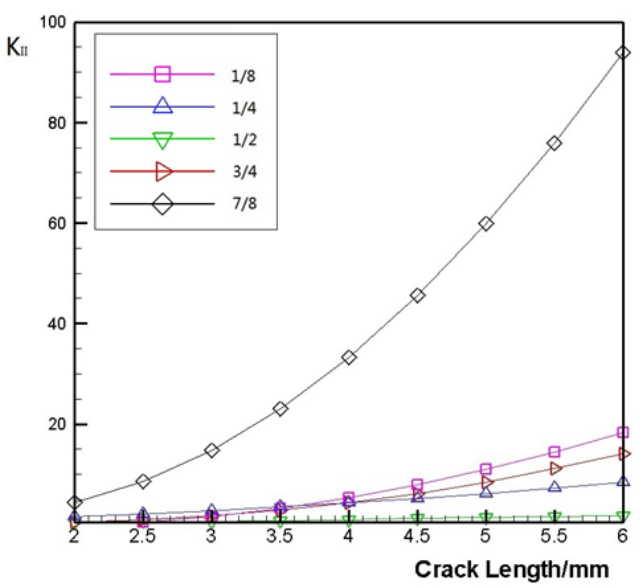

(b) $\mathrm{K}_{\mathrm{II}}$ Vs crack length

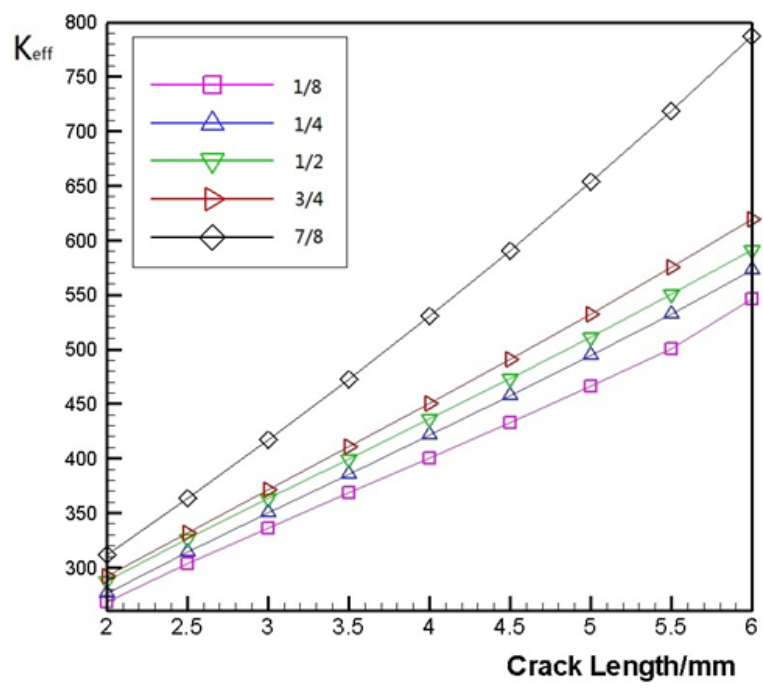

(c) $\mathrm{K}_{\text {eff }}$ Vs crack length

Fig.3 SIF varies with the crack length and its position

From Figure 3(a) it can be seen that for the cracks with the same length, $\mathrm{K}_{\mathrm{I}}$ is getting larger and larger as the crack is closer to the loaded edge. It is also found that at the same location $K_{I}$ increases with the increasing crack length. Different for $K_{I}$, The maximum $K_{I I}$ occurs at the $x / L=7 / 8$ position and the minimum $\mathrm{K}_{\mathrm{II}}$ occurs in the middle position between the fixed edge and loaded edge of the rectangular plate, as shown in Fig. 3(b). The $\mathrm{K}_{\mathrm{II}}$ 's almost does not depend on the position of the cracks at the positions of $\mathrm{x} / \mathrm{L}=1 / 8,1 / 4$, and $3 / 4$ as crack length $a$ is smaller than $4 \mathrm{~mm}$ for the group of cracks. From Fig.3(c) it is found that variation tendency of $K_{\text {eff }}$ with crack length and position is the similar to ones of $\mathrm{K}_{\mathrm{I}}$. Comparing Fig. 3 (a) with (b), this is not difficult to understand that $\mathrm{K}_{\mathrm{I}}$ is one order larger than $\mathrm{K}_{\mathrm{II}}$, i.e. $\mathrm{K}_{\text {eff }}$ is dominated by $\mathrm{K}_{\mathrm{I}}$. Some of the phenomenon might be related to the displacement contour, as shown in Figure 4. The figure shows the change of displacement of the plate with a crack of $a=5 \mathrm{~mm}, \mathrm{x} / \mathrm{L}=1 / 2$ and $a=5 \mathrm{~mm}, \mathrm{x} / \mathrm{L}=7 / 8$. In the figure blue color represents the zero displacement, red color shows the largest displacement. Comparing Fig. 4(a) with (b), it is seen that the deformation is more remarkable in the region of crack at the position of $x / L=7 / 8$ than the one $\mathrm{x} / \mathrm{L}=1 / 2$. 

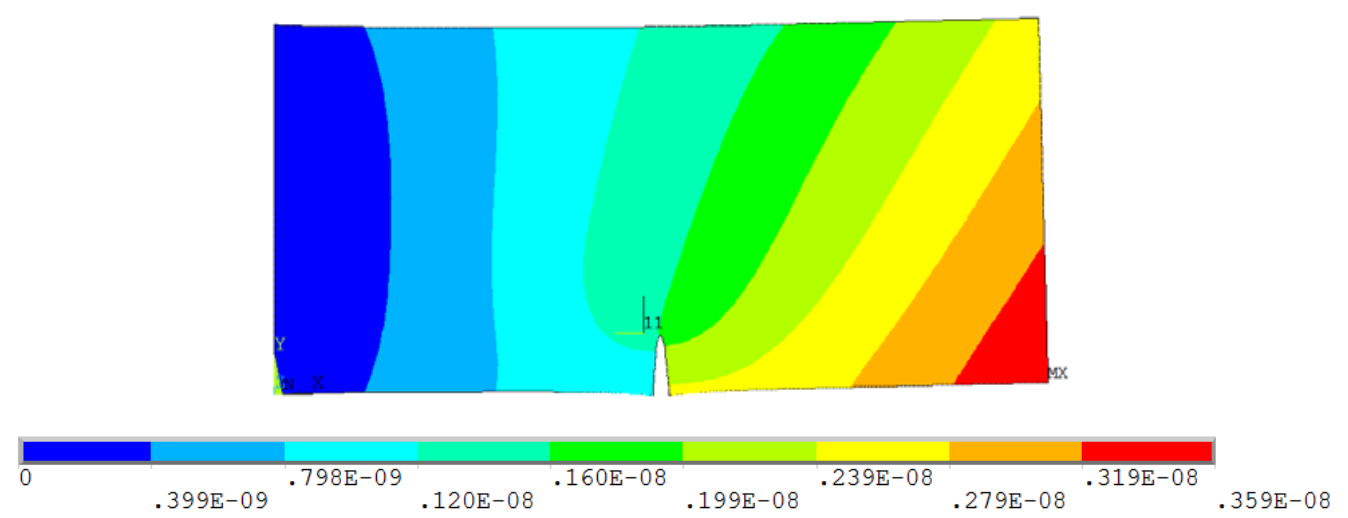

(a)

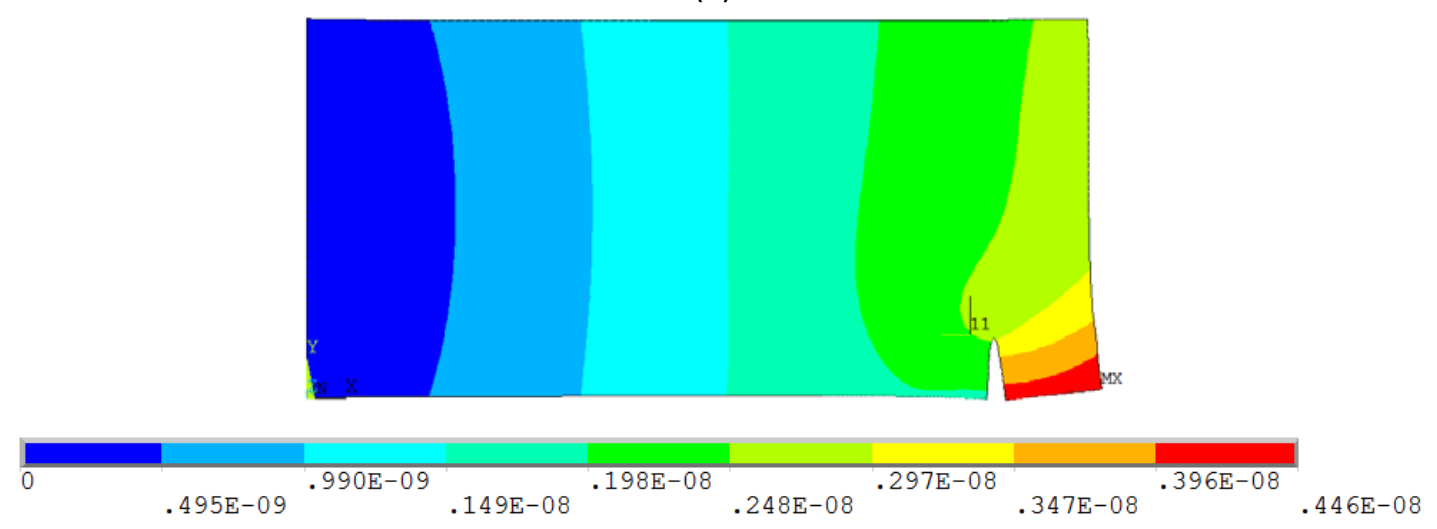

(b)

Fig.4 Displacement contour of plate with a crack of (a) $a=5 \mathrm{~mm}, \mathrm{x} / \mathrm{L}=1 / 2$ and (b) $a=5 \mathrm{~mm}, \mathrm{x} / \mathrm{L}=7 / 8$

Fig. 5 shows the relationship between the crack mouth opening displacement, the crack length and position. It is shown that the crack opening displacement increases with the increasing crack length. The position with the maximum crack mouth opening displacement corresponds to position closest to the loading edge. The CMOD at the position is significantly larger than ones at other positions. The crack which is located at the middle between the fixed edge and loading edge has a minimum opening displacement. The opening displacements of cracks at other positions are slightly larger than one at the middle position and far smaller than one nearest to the loading edge. It is worth noting that, comparing Fig.5 with Fig 3, there is no any correlation between SIF and CMOD.

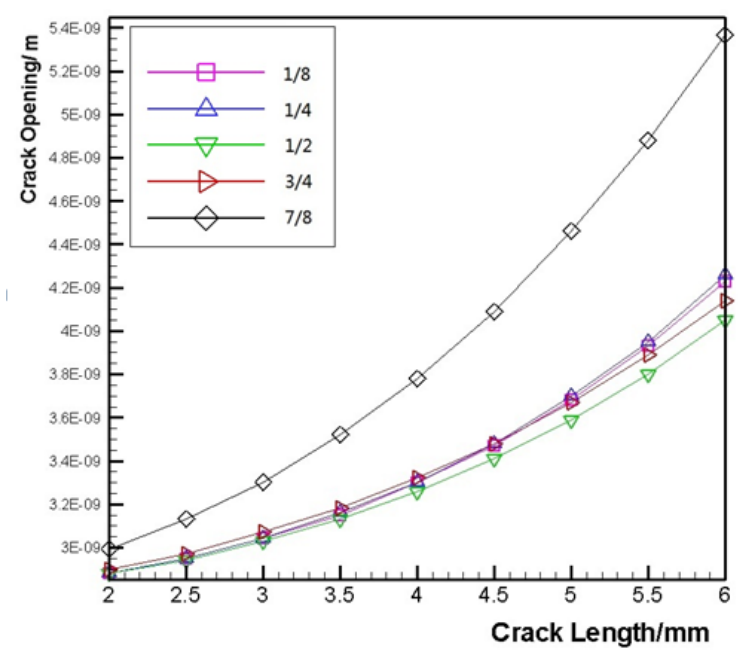

Fig.5 Crack mouth opening displacement 


\section{Conclusion}

ANSYS finite element software is used to calculate stress intensity factor of SENT of clam steel plate. It can be conclude that $K_{I}$ is one order larger than $K_{I I}$ and dominates the value of $K_{\text {eff. }} K_{I}$ of crack nearest to loading edge is larger than ones of cracks at the other positions. is closer to the loaded edge, and increases with the growth of the crack length. The opening displacements of crack nearest to the loading edge is the largest and at the middle is smallest. Any correlation is not found between stress intensity factor and crack mouth opening displacement.

\section{Acknowledgements}

The work was supported by NSFC (No. 51231002 and 11274110).

\section{References}

[1] Lakkundi A B, Soschinske K A A. Prediction of crack growth in aircraft engine bleed air ducts using finite element and crack growth analysis[J]. Copyright Avinash Basavraj Lakkundi All Rights Reserved, 2006.

[2] Li D, Yang H, Lu Y. Numerical analysis of SIF and security service evaluation on thin-walled pipeline's semi-elliptical crack in NPS under heat-stress coupling load[J]. Procedia Engineering, 2012, 27:1582-1587.

[3] Abdullah S, Ariffin A K, Ghazali M J, et al. Finite Element Analysis on the Stress Intensity Factor under Combined Bending and Torsion Loading[J]. Key Engineering Materials, 2011, 462-463:1325-1330..

[4] Sultan A, Pasha R A, Ali M, et al. Numerical Simulation and Experimental Verification of CMOD in SENT Specimen: Application on FCGR of Welded Tool Steel[J]. Acta Metallurgica Sinica, 2013, 26(1):92-96.

[5] Ge H, Peng L, Dai Y, et al. Tensile properties of CLAM steel irradiated up to 20.1 dpa in STIP-V[J]. Journal of Nuclear Materials, 2015. 